\title{
Preventing oxygen free radical damage by proanthocyanidin in obstructive jaundice
}

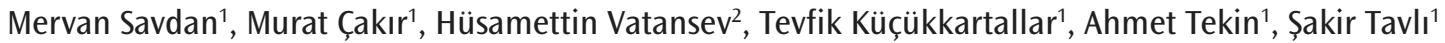

\section{ABSTRACT}

Cite this paper as: Savdan M, Çakır M, Vatansev H, Küçükkartallar T, Tekin A, Tavlı Ş. Preventing oxygen free radical damage by proanthocyanidin in obstructive jaundice. Turk J Surg 2017; 33(2): 62-68

'Department of General Surgery, Necmettin Erbakan University Meram School of Medicine, Konya, Turkey

2Department of Biochemistry, Selçuk University School of Medicine, Konya, Turkey

This study was presented at the $51^{\text {st }}$ Congress of the European Society for Surgical Research, 25-28 May 2016, Prague, Czech Republic.

Address for Correspondence Murat Çakır

e-mail:drmuratcakir@hotmail.com

Received: 16.08.2015

Accepted: 19.10.2015

(C) Copyright 2017 by Turkish Surgical Association
Objective: Tissue damage and endotoxemia in obstructive jaundice are attributed to the increase in oxygen freeradicals. We aimed at evaluating the possible protective effect of grape seed proanthocyanidin extract (GSPE), which is a potent exogenous free-radical scavenger and antioxidant.

Material and Methods: The study was performed at the Necmettin Erbakan University Meram School of Medicine Research and Application Center for Experimental Medicine Laboratory with ethical approval. 30 Wistar-Albino rats were used and were divided into 3 groups. The common bile duct was identified and only dissected in the first group (sham). Following dissection of the common bile duct it was ligated with $4 / 0$ silk just above the pancreas in the second group (control). After ligation of the common bile duct, $100 \mathrm{mg} / \mathrm{kg} /$ day GSPE was administered via orogastric lavage for 10 days in the third group.

Results: Biochemical values revealed a statistically significant difference between Group I and the others. There was no difference between Group II and III regarding biochemical values. There was a statistically significant difference, however, between Group II and III with regards to nitric oxide levels. There was a statistically significant difference between Group I and the other groups concerning hepatic and pulmonary tissue damage on histopathologic evaluation. There was no difference among the groups with regards to renal tubular damage.

Conclusion: Proanthocyanidin is an effective natural antioxidant in decreasing the level of tissue damage caused by oxygen free-radicals.

Keywords: Antioxidant, jaundice, proanthocyanidin

\section{INTRODUCTION}

The condition caused by the obstruction of extrahepatic bile ducts for any reason is called obstructive jaundice. This condition generally needs to be treated surgically. Major complications like sepsis, renal failure, and pulmonary dysfunction are frequently seen in these patients. The toxic effects of elevated levels of bile salt and bilirubin in the cell cause local damage, while the released mediators result in systemic complications (1). These alterations lead to hepatocyte damage, portal and systemic endotoxemia, liquid electrolyte loss, and malnutrition (1, 2). It has been reported that tissue damage and endotoxemia related to obstructive jaundice causes an increase in the production of oxygen free-radicals which in turn increases lipid peroxidation $(3,4)$.

Oxygen free radicals impair both the cellular membrane and intracellular structures. Antioxidant materials with decreased secondary intestinal absorption and decreased plasma levels cause failure in fat absorption and increase oxidative damage in obstructive jaundice $(5,6)$. Oxidant damage and lipid peroxidation aggravate the already existing hepatic damage in obstructive jaundice $(7,8)$.

Proanthocyanidins, which are potent natural antioxidant compounds, are found in dried nuts and fruits, seeds, vegetables, fruits, and barks. Proanthocyanidins refer to a specific group of flavonoids that are polyphenolic compounds. Proanthocyanidins demonstrate their free-radical scavenger and antioxidant activity through vasodilator, anti-carcinogenic, anti-allergic, anti-inflammatory, antibacterial, cardio-protective, immune-stimulant, antiviral, estrogenic effects related to cyclooxygenase, phospholipase A2, and lipooxygenase inhibition (9-11).

In this experimental study, we aimed at evaluating the possible protective effect of grape seed proanthocyanidin extract (GSPE) which is a potent exogenous free-radical scavenger and antioxidant.

\section{MATERIAL AND METHODS}

The study was carried out at the Research and Application Center for Experimental Medicine Laboratory of Necmettin Erbakan University with the consent of the ethical board (31.10.2012-2012/86). 30 Wistar-Albino rats weighing approximately 200-250 gr were used in the study. The animals were fed with unlimited standard rat feed and tap water during the course of the experiment. Five rats were placed in each cage 
and after they got adapted to laboratory conditions, they were randomly divided into 3 groups of 10 rats.

Anesthesia and Surgical Procedure: In all surgical procedures anesthesia was secured through intraperitoneal administration of $100 \mathrm{mg} / \mathrm{kg}$ ketamine $\mathrm{HCl}$ (Ketalar vial; Parke-Davis, Morris Plains) and $25 \mathrm{mg} / \mathrm{kg}$ Xylazine $\mathrm{HCl}$ (Rompon vial, Bayer). Following anesthesia, the abdominal areas of all animals were shaved. The abdominal area was cleaned with $10 \%$ povidone iodine. Laparotomy was performed with a $3 \mathrm{~cm}$ mid-line incision. The common bile duct was identified and only dissected in the first group (sham group). Following dissection of the common bile duct, it was ligated with $4 / 0$ silk just above the pancreas in the second group (control group). After ligation of the common bile duct, the rats were administered $100 \mathrm{mg} / \mathrm{kg} /$ day GSPE through orogastric lavage (under anesthesia) for 10 days in the third group (treatment group). The abdominal wall of all groups were closed with $3 / 0$ polyglactin sutures.

Sampling: All animals were sacrificed by high dose anesthetic material at the end of day 10. Following laparotomy and sternotomy, 5 cc of blood was drawn from the heart for biochemical analysis and tissue samples were obtained from the liver and kidneys for pathologic evaluation.

Biochemical Analysis: Total bilirubin (T.Bil), direct bilirubin (D.Bil), aspartate aminotransferase (AST), alanine aminotransferase (ALT), alkaline phosphatase (ALP), gamma glutamyl transferase (GGT), urea, creatinine, serum nitric oxide (NO), and malondialdehyde (MDA) levels were analyzed. Blood samples were analyzed by Olympus/AU 5200 (Konsesyum, Alternative Biomedical Services, Dallas, TX, USA). Serum nitric oxide (NO) measurements were carried out by ELISA method using nitric oxide colorimetric assay kits. MDA measurements were manually conducted by Perkin Elmer lambda 25/UV-Vis spectrometers.

Pathologic Evaluation: All tissues were placed in 10\% formalin solution for 24 hours for fixation. Tissue tracking procedure was carried out for 16 hours in an autotechnicon processor (Leica ASP300). $5 \mu \mathrm{m}$-wide sections were obtained from tissues buried in paraffin blocks using microtome knives onto lysine slides. The samples were stained with hematoxylin eosin. The preparations with completed staining were evaluated by a single pathologist using Olympus BX51 light microscope. The tissues were scored according to the following features.

For the Lungs: A tissue damage evaluation scale was used as was stated in an article by Özdülger et al. (12). In this scale:

Grade 1 refers to normal pulmonary histology,

Grade 2 to mild neutrophil leukocyte infiltration,

Grade 3 to moderate neutrophil leukocyte infiltration, perivascular edema formation, partial destruction in pulmonary structure, and

Grade 4 refers to intensive neutrophil leukocyte infiltration, total destruction in pulmonary structure.

For the Kidneys: Granulovacuolar degeneration and widening in renal tubules were evaluated in 5 grades semi-quanti- tatively as stated by Chen et al. (13): Grade 1: No renal tubule damage, Grade 2: Renal tubule damage $>25 \%$, Grade 3: Renal tubule damage $25-0 \%$, Grade 4: Renal tubule damage 50-75\%, Grade 5: Renal tubule damage $75-100 \%$.

For the Liver: Microabscess caused by cholestasis, widened bile canaliculi, necrosis located in the portal area in the liver were evaluated by light microscopy. The evaluation of bile infarctions and portal area necrosis was carried out according to the largest necrosis area and the size of the biliary infarct area (14): Grade 1: No biliary infarction and necrosis, Grade 2: The size of the biliary infarction and necrosis is smaller than 1 large enlargement field, Grade 3: The size of the biliary infarction and necrosis is equal to 1 large enlargement field, Grade 4: The size of the biliary infarction and necrosis is larger than 1 large enlargement field.

Statistical Analysis: The data collected within the framework of this study was evaluated by Statistical Package for the Social Sciences SPSS 15.0 package program (SPSS Inc.; Chicago, IL, USA). Following the execution of the normality test, the differences among groups were studied and non-normally distributed variables in binary groups were studied by the Mann-Whitney $U$ test, while those with normal distribution were evaluated by the Student T test.

While evaluating the differences among the groups, significance level was set at 0.05 and in cases where $p<0.05$ it was stated that there was a significant difference among groups while in cases where $p>0.05$ it was expressed as no significant difference among groups.

\section{RESULTS}

There was a decrease in daily food and water consumption in the control and treatment groups. Weight loss and tardiness in movement was observed in the groups with obstructive

$$
\text { Table 1. Biochemical parameters }
$$

\begin{tabular}{lccc}
\hline Parameters & Group 1 & Group 2 & Group 3 \\
\hline $\begin{array}{l}\text { Total bilirubin } \\
(\mathrm{mg} / \mathrm{dL})\end{array}$ & $0.11 \pm 0.00^{\mathrm{a}, \mathrm{c}}$ & $13.84 \pm 4.84$ & $12.72 \pm 5.10$ \\
\hline
\end{tabular}

Direct bilirubin
$(\mathrm{mg} / \mathrm{dL})$

$\operatorname{ALT}(\mathrm{U} / \mathrm{dL}) \quad 64.75 \pm 16.40^{\mathrm{a}, \mathrm{c}} \quad 172.29 \pm 116.04$

$175.86 \pm 66.91$

\begin{tabular}{|lccc|}
\hline ALP $(\mathrm{U} / \mathrm{dL})$ & $117.5 \pm 39.8^{\mathrm{a}, \mathrm{c}}$ & $307.5 \pm 144.5$ & $363.1 \pm 107.3$ \\
\hline GGT $(\mathrm{U} / \mathrm{dL})$ & $4.0 \pm 0.00^{\mathrm{a}, \mathrm{c}}$ & $20.14 \pm 9.35$ & $24.14 \pm 8.15$ \\
\hline Urea $(\mathrm{mg} / \mathrm{dL})$ & $87.6 \pm 3.31$ & $47.88 \pm 3.81$ & $44.54 \pm 3.71$ \\
\hline Creatinine $(\mathrm{mg} / \mathrm{dL})$ & $0.43 \pm 0.02^{\mathrm{a}, \mathrm{c}}$ & $0.34 \pm 0.37$ & $0.2 \pm 0.22$ \\
\hline NO $(\mathrm{mmoL} / \mathrm{L})$ & $1.45 \pm 0.05^{\mathrm{a}, \mathrm{c}}$ & $4.92 \pm 0.43^{\mathrm{b}}$ & $3.62 \pm 0.36$ \\
\hline MDA $(\mu \mathrm{M} / \mathrm{mg}$ prot $)$ & $11.70 \pm 0.88^{\mathrm{a}, \mathrm{c}}$ & $19.48 \pm 3.22^{\mathrm{b}}$ & $20.1 \pm 2.97$
\end{tabular}

AST: aspartate aminotransferase; ALT: alanine aminotransferase; ALP: alkaline phosphatase; GGT: gamma glutamyl transferase; NO: nitric oxide; MDA: malondialdehyde; SD: standard deviation

Values are presented as mean \pm SD

a: group 1 vs group $2(p<0.05)$

b: group 2 vs group $3(p<0.05)$

c: group 1 vs group $3(p<0.05)$ 

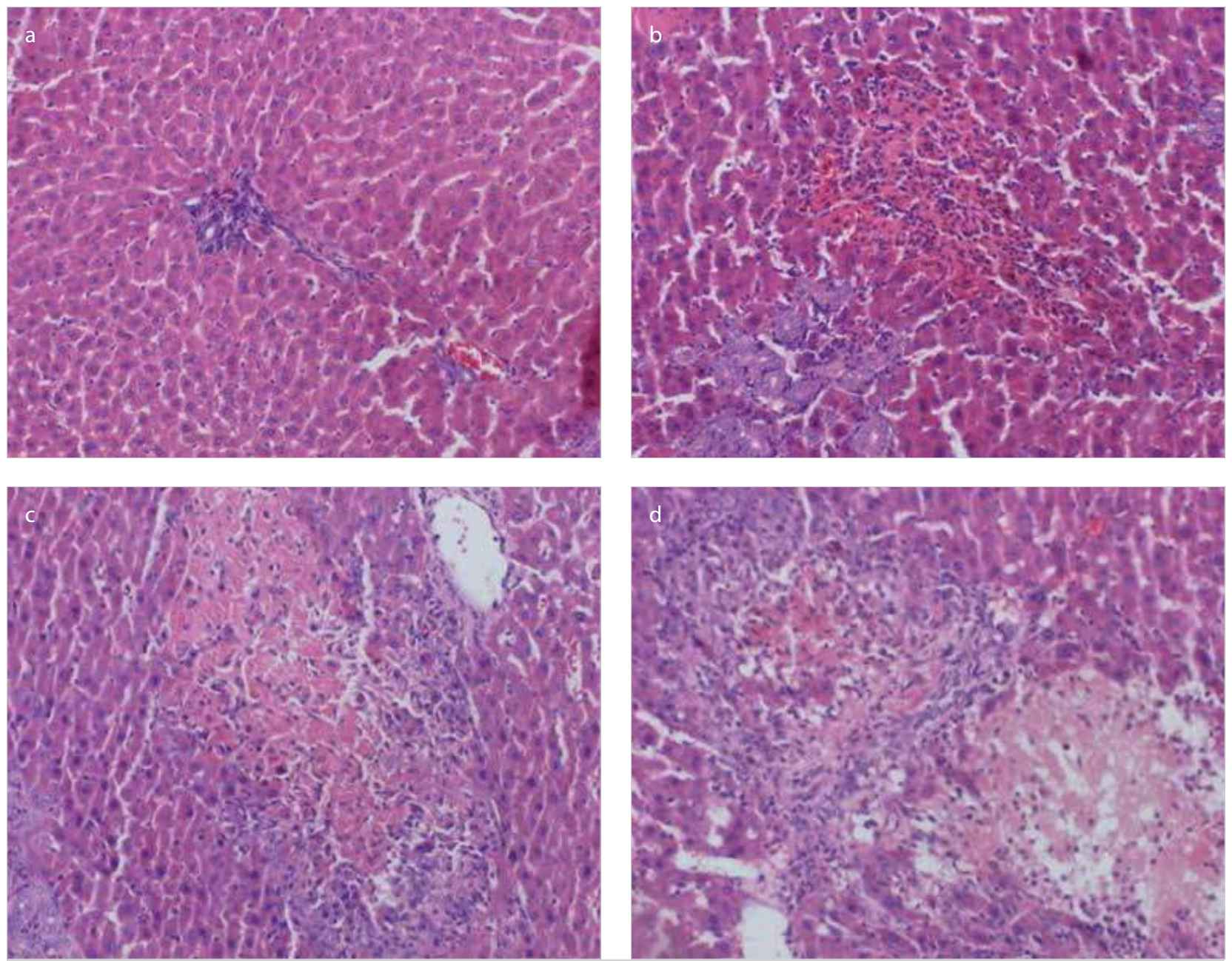

Figure 1. a-d. Hepatic histopathologic views. (a) normal (group 1), (b) grade I (group 1), (c) grade II (groups 1-3), (d) grade III (groups 2-3) damage. The necrosis and microabscess shown are related to cholestasis (hematoxylin and eosin x40)

\begin{tabular}{|c|c|c|c|c|c|c|c|c|c|}
\hline \multicolumn{2}{|c|}{ Histopathologic changes } & \multicolumn{2}{|c|}{ Group 1 (\%) } & \multicolumn{3}{|c|}{ Group 2 (\%) } & \multicolumn{3}{|c|}{ Group 3 (\%) } \\
\hline & Liver $\mathrm{a}, \mathrm{c}$ & Kidney & Lung ${ }^{a, c}$ & Liver $\mathrm{a}, \mathrm{b}$ & Kidney & Lung ${ }^{a, b}$ & Liver ${ }^{b, c}$ & Kidney & Lung ${ }^{b, c}$ \\
\hline Grade 1 & 60 & 30 & 50 & 0 & 0 & 0 & 0 & 0 & 0 \\
\hline Grade 2 & 40 & 70 & 50 & 0 & 0 & 0 & 20 & 20 & 50 \\
\hline Grade 3 & 0 & 0 & 0 & 30 & 40 & 40 & 60 & 50 & 50 \\
\hline Grade 4 & 0 & 0 & 0 & 70 & 40 & 60 & 20 & 30 & 0 \\
\hline Grade 5 & & 0 & & & 20 & & & 0 & \\
\hline \multicolumn{10}{|c|}{$\begin{array}{l}\text { Values are presented as } \% . \\
\text { a: Group } 1 \text { vs Group } 2(p<0.05) \\
\text { b: Group } 2 \text { vs Group } 3(p<0.05) \\
\text { c: Group } 1 \text { vs Group } 3(p<0.05)\end{array}$} \\
\hline
\end{tabular}

jaundice. The re-laparotomy revealed only intraabdominal adhesions in the sham group. In addition to intraabdominal adhesions, there was edema in the liver and kidneys as well as gallbladder hydrops in the control and treatment group rats. Any macroscopically significant change was not detected in the lungs.

Biochemical evaluation revealed a statistically significant difference between Group I and other groups. There was no difference between Group II and III in terms of biochemical ference between Group II and III with regards to the NO value (Table 1).

Results of Histopathologic Evaluation: There was a statistically significant difference between Group I and the others regarding hepatic and pulmonary damage $(p<0.05)$ (Figure 1,2$)$. There was no difference among the groups in terms of renal tubular damage ( $p>0.05$ ) (Figure 3). While there was a significant difference between Group II and III regarding hepatic and pulmonary damage, but no difference was detected between these two groups in terms of renal damage. All histopathologic findings are summarized in Table 2. 

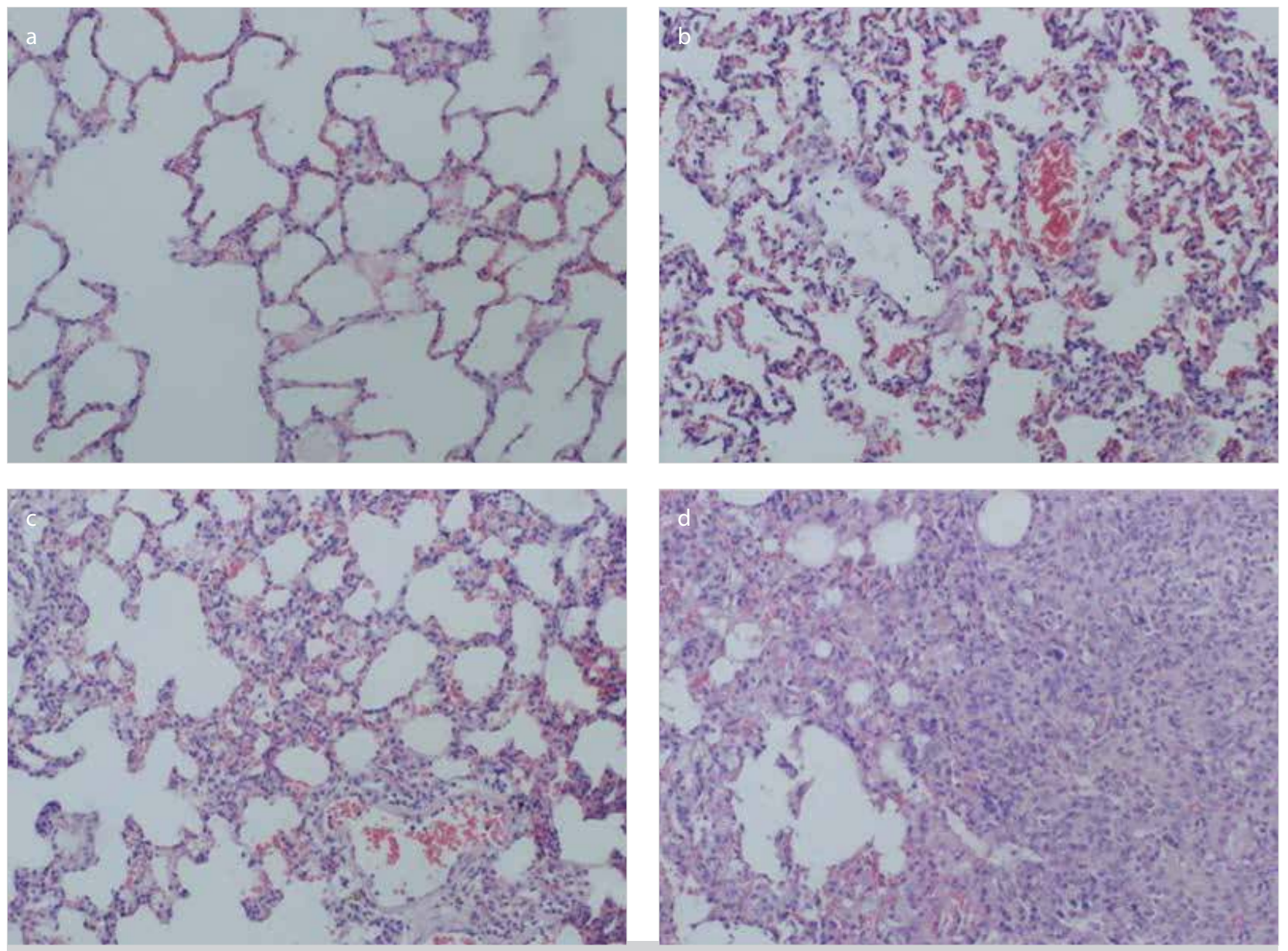

Figure 2. a-d. Pulmonary histopathologic views. (a) grade I (group 1), (b) grade II (groups 1-3), (c) grade III (groups 2-3), (d) grade IV (group 2) damage (hematoxylin and eosin, $x 100$ )

\section{DISCUSSION}

Obstructive jaundice is related to the impairment of bile flow from the liver into the gastrointestinal system due to obstruction in the intra- and extra-hepatic bile ducts. Major hepatic complications of prolonged obstructive jaundice include cholangitis, coagulation defects, biliary fibrosis and cirrhosis as a result of progressive hepatic damage. Complications such as sepsis, renal failure, and pulmonary dysfunction are frequently seen in patients with obstructive jaundice in the post-operative period (15). The toxic effects of elevated intracellular bile salts and bilirubin lead to portal and systemic endotoxemia, fluid-electrolyte imbalances, and malnutrition (2). Alterations in intestinal flora, intestinal mucosal barrier, and the immune system can be observed since flow of bile to the intestine is blocked (2). There is a correlation between high serum bilirubin levels and operative mortality in patients with jaundice (16). The most important two factors for morbidity and mortality in the post-operative period for bile duct procedures in patients with obstructive jaundice are sepsis and renal failure (17). Other conditions that arise in obstructive jaundice are the disorder in the balance of hepatic oxidative antioxidant systems and the increase in lipid peroxidation $(3,18)$. The gradual increase in the number of recent studies suggests that prevention of oxidative stress can play a significant role in preventing cholestatic hepatic damage. In a study on the effects of antioxidants in bile duct obstruction, Kawada et al. (19) stated that there was a disorder in the functions of hepatic stellate and Kupffer's cells in rats. In that study resveratrol, quercetin, and acetylcysteine have improved the scope of the damage caused by the regulatory functions of these two cells. This effect was associated with the antioxidant features of the agents used. Based on this, we investigated the effects of proanthocynidin, which is a potent antioxidant, on obstructive jaundice.

For the last 2-3 decades, it has been known that oxygen freeradicals (OFR) play a role in several pathologies including cancer (20). OFR are produced by parenchymal, endothelial and inflammatory cells. Their cytotoxic effects emerge when their levels are elevated and they are released out of the cell. The decrease in oxygen free-radical levels also lead to a decrease in tissue damage and accelerate healing (20). If oxidants surpass certain levels or if antioxidants prove to be insufficient, that is if the balance is lost; then protein, lipid, carbohydrate, nucleic acid, and enzymes, which are the structural elements of the organism, are impaired. In many diseases, elevated levels of reactive oxygen radicals (ROR) are not the main cause of the disease. They, however, are formed secondary to the primary disorder and subsequently play a part in pathogenesis (21). Proanthocyanidins are natural, potent antioxidant substances (22). Their antioxidant properties are very strong, Bagchi et al. (10) reported that they were stronger than Vitamin C, Vitamin E, and $\beta$-carotene (23). The inhibition level of the superoxide anion and hydroxyl radical by $100 \mathrm{mg} / \mathrm{L}$ concentration of grape seed proanthocyanidin extract was found to be $78 \%$ 

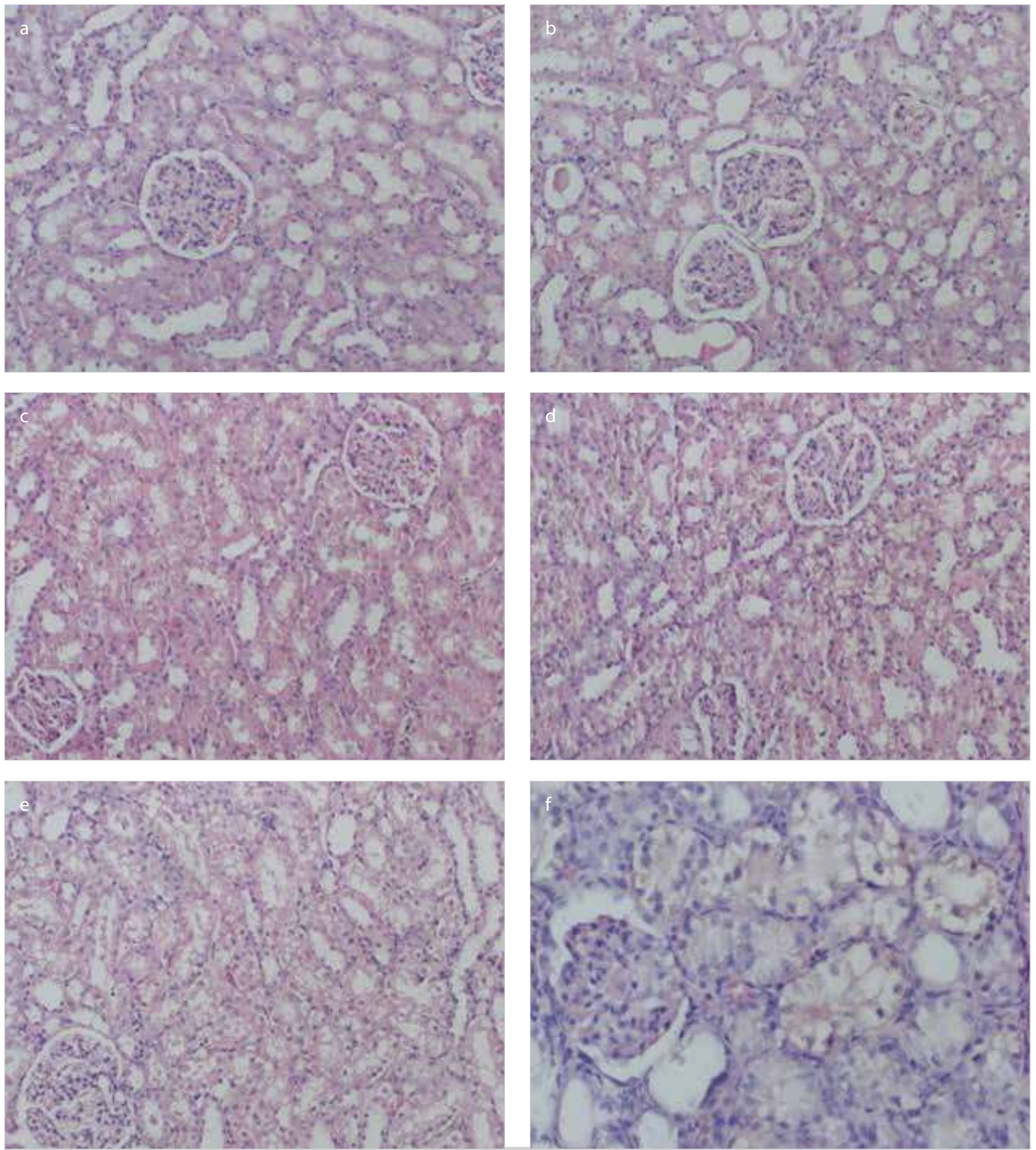

Figure 3. a-f. Renal histopathologic views. (a) grade I (group 1), (b) grade II (groups 1-3), (c) grade III (groups 2-3), (d) grade IV (Group 2-3), and (e, f) grade V (group 2) damage

(Figure a-e: hematoxylin and eosin x100, Figure f: hematoxylin and eosin x200)

and $81 \%$, respectively. It yielded a better antioxidant effect than same dosage of Vitamin C (12\% vs $19 \%)$ or Vitamin E (36\% vs 44\%) (22). Furthermore, proanthocyanidin has also been reported to have anti-carcinogenic, anti-inflammatory, anti-bacterial, anti-viral, cardioprotective, and immune system stimulant properties by inhibiting phospholipase $\mathrm{A} 2$, cyclooxygenase, and lipooxygenase enzymes $(22,23)$. When the MDA and NO levels, which show lipid peroxydation following obstructive jaundice, were compared it was found in our study that both parameters were significantly low in the sham group. However, there was no statistically significant difference in MDA levels of the treatment group in compari- son to the control group. There was significant difference in the treatment group in comparison to the control group with regards to NO levels. Our study results indicated that proanthocyanidin decreases lipid peroxidation, oxidative stress, neutrophil migration, and pulmonary damage.

Obstructive jaundice is associated with biliary infarctions and portal changes. Biliary infarction is related to the ductal damage due to increased biliary pressure, the direct effect of bile components on hepatocytes, and the indirect effects of bilirubin and bile acids in the blood (24). Edema, and neutrophil and lymphocyte infiltration can be observed in the first week 
following obstruction. Portal inflammation and bile duct proliferation in the periportal area can also be seen (24). In our study, there was a statistically significant decrease in the treatment group in terms of liver micro-abscess and necrosis as compared to the control group $(p<0.05)$. We determined that proanthocyanidins, which were selected due to their antioxidant properties, yielded a significant improvement on histopathologic disorders in obstructive jaundice. However, this improvement was not reflected in biochemical parameters and did not reach statistical significance. We also identified a significant improvement in the treatment group regarding NO levels, which are the best indicators of an antioxidant effect.

Chang and Ohara (25) detected cells resembling large mononuclear macrophages containing latex particles in the pulmonary capillaries of lung parenchyma in rats with obstructive jaundice. In these rats with obstructive jaundice, there was an increase in intravascular phagocytosis that led to pulmonary edema, which was reported to cause an inclination for sepsis and ARDS. We observed a significant decrease in pulmonary neutrophil leukocyte infiltration in the treatment group in comparison to the control group $(p<0.05)$. Although the etiology of renal function disorders in obstructive jaundice is yet to be known, it has been suggested that cellular and extracellular hypovolemia, increase in oxygen free radicals, and decrease in antioxidant functions play a significant role $(26,27)$. While there was a decrease in the scope of renal tubule damage in the treatment group of our study, it was not statistically significant.

\section{CONCLUSION}

In conclusion, we have shown in our study that proanthocyanidin administration significantly decreased liver microabscess and necrosis as well as neutrophil migration in the lungs in obstructive jaundice. Furthermore, we have demonstrated that although it did not reach statistical significance, proanthocyanidin administration also reduced renal tubule damage. This improvement was also detected in NO levels. We concluded that proanthocyanidin is a natural antioxidant that is effective in reducing the scope of tissue damage caused by oxygen free radicals.

Ethics Committee Approval: Ethics committee approval was received for this study from the ethics committee of Necmettin Erbakan University (31.10.2012-2012/86).

Informed Consent: Not required in this study.

Peer-review: Externally peer-reviewed.

Author Contributions: Concept - M.Ç.; Design - M.Ç.; Supervision - Ş.T.; Resource - T.K.; Materials - M.Ç.; Data Collection and/or Processing M.S.; Analysis and/or Interpretation - A.T.; Literature Search - M.S.; Writing Manuscript - M.Ç.; Critical Reviews - A.T., H.V.

Acknowledgements: The authors would like to thank Dr. Hakan Esen for this contributions.

Conflict of Interest: No conflict of interest was declared by the authors.

Financial Disclosure: The authors declared that this study has received no financial support.

\section{REFERENCES}

1. Schwartz SL Liver. In: Schwartz SI, Shires GT, Spencer FC, Husser WC (eds). Principles of Surgery $\left(7^{\text {th }}\right)$. Mc Graw-Hill, Philadelphia 1999.

2. Hoshino S, Sun Z, Uchikura K, Tsugane K, Ceppa E, Bulkley GB, et al. Biliary obstruction reduces hepatic killing and phagocytic clearance of circulating microorganisms in rats. J Gastrointest Surg 2003; 7: 497-506. [CrossRef]

3. Galicia-Moreno M, Rodríguez-Rivera A, Reyes-Gordillo K, Segovia J, Shibayama M, Tsutsumi V, et al. N-acetylcysteine prevents carbon tetrachloride-induced liver cirrhosis: role of liver transforming growth factor-beta and oxidative stress. Eur J Gastroenterol Hepatol 2009; 21: 908-914. [CrossRef]

4. Labieniec M, Przygodzki T, Cársky J, Malinska D, Rysz J, Watala C. Effects of resorcylidene aminoguanidine (RAG) on selected parameters of isolated rat liver mitochondria. Chem Biol Interact 2009; 15: 280-287. [CrossRef]

5. Celik VK, Eken IE, Yildiz G, Yilmaz MB, Gurlek A, Aydin H. Vitamin E and antioxidant activity; its role in slow coronary flow. Cardiovasc J Afr 2013; 24: 360-363. [CrossRef]

6. Canturk NZ. Cytoprotective effects of alpha tocopherol against liver injury induced by extrahepatic biliary obstruction. East Afr Med J 1998; 75: 77- 80.

7. Weber-Mzell D, Zaupa P, Petnehazy T, Kobayashi H, Schimpl $G$, Feierl G, et al. The role of nuclear factor-kappa B in bacterial translocation in cholestatic rats. Pediatr Surg Int 2006; 22: 43-49. [CrossRef]

8. Kesik V, Kurt B, Tunc T, Karslioglu Y, Citak EC, Kismet E, et al. Melatonin ameliorates doxorubicin-induced skin necrosis in rats. Ann Plast Surg. 2010; 65: 250-253. [CrossRef]

9. Morin B, Narbonne JF, Ribera D, Badouard C, Ravanat JL. Effect of dietary fat-soluble vitamins $A$ and $E$ and proanthocyanidin-rich extract from grape seeds on oxidative DNA damage in rats. Food Chem Toxicol 2008; 46: 787-796. [CrossRef]

10. Bagchi D, Garg A, Krohn RL, Bagchi M, Bagchi DJ, Balmoori J, et al. Protective effects of grape seed proanthocyanidins and selected antioxidants against TPA-induced hepatic and brain lipid peroxidation and DNA fragmentation, and peritoneal macrophage activation in mice. Gen Pharmacol 1998; 30: 771-776. [CrossRef]

11. Rice-Evans CA, Miller NJ, Paganda G. Structure antioxidant activity relationships of flavonoids and phenolic acids. Free Rad Biol Med 1996; 20: 933- 956. [CrossRef]

12. Ozdulger A, Cinel I, Koksel O, Cinel L, Avlan D, Unlu A, et al. The protective effect of $\mathrm{N}$-Acetylcysteine on apoptotic lung injury in cecal ligation and puncture-induced sepsis model. Shock 2003; 19: 366-372. [CrossRef]

13. Chen CY, Shiesh SC, Tsao HC, Chen FF, Lin XZ. Protective effect of melatonin on renal injury of rats induced by bile ligation. Dig Dis Sci 2001; 46: 927-931. [CrossRef]

14. Tsai LY, Lee KT, Lu FJ. Biochemical events associated with ligation of the common bile duct in Wistar rats. J Formos Med Assoc 1997; 96: 17-22.

15. Togawa $O$, Isayama $H$, Tsujino $T$, Nakai $Y$, Kogure $H$, Hamada $T$, et al. Management of dysfunctional covered self-expandable metallic stents in patients with malignant distal biliary obstruction. J Gastroenterol 2013; 48: 1300-1307. [CrossRef]

16. Dixon JM, Armstrong CP, Duffy SW, Davies GC. Factors affecting morbidity and mortality after surgery for obstructive jaundice: a review of 373 patients. Gut 1983; 24: 845-852. [CrossRef]

17. Dixon JM, Armstrong CP, Duffy SW, Elton RA, Davies GC. Factors affecting mortality and morbidity after surgery for obstructive jaundice. Gut 1984; 25: 104-107. [CrossRef]

18. Pacini N, Prearo M, Abete MC, Brizio P, Dörr AJ, Reimschuessel R, et al. Antioxidant responses and renal crystal formation in rainbow trout treated with melamine administered individually or in combination with cyanuric acid. J Toxicol Environ Health A 2013; 76: 491-508. [CrossRef] 
19. Kawada N, Seki S, Inoue M, Kuroki T. Effect of antioxidants, resveratrol, quercetin, and $\mathrm{N}$-acetylcysteine, on the functions of cultured rat hepatic stellate cells and Kupffer cells. Hepatology 1998; 27: 1265-1274. [CrossRef]

20. Bast A, Haenen GR, Doelman CJ. Oxidants and antioxidants: state of art. Am J Med 1991; 91: 2-7. [CrossRef]

21. Arul D, Subramanian P. Inhibitory effect of naringenin (citrus flavonone) on $\mathrm{N}$-nitrosodiethylamine induced hepatocarcinogenesis in rats. Biochem Biophys Res Commun 2013; 434: 203-209. [CrossRef]

22. Karaaslan O, Ulusoy MG, Kankaya Y, Tiftikcioglu YO, Kocer U, Kankaya D, et al. Protective effect of grape seed extract against ischemia/reperfusion injury in a rat epigastric flap model. J Plast Reconstr Aesthet Surg 2010; 63: 705-710. [CrossRef]

23. Sizlan A, Guven A, Uysal B, Yanarates O, Atim A, Oztas E, et al. Proanthocyanidin protects intestine and remote organs against mesenteric ischemia/reperfusion injury. World J Surg 2009; 33: 1384-1391. [CrossRef]

24. Bagchi D, Sen CK, Ray SD, Das DK, Bagchi M, Preuss HG, et al. Molecular mechanisms of cardioprotection by a novel grape seed proanthocyanidin extract. Mutat Res 2003; 523: 87-97. [CrossRef]

25. Chang SW, Ohara N. Chronic Biliary Obstruction Induces Pulmonary Intravascular Phagocytosis and Endotoxin Sensitivity in rats. J Clin Invest 1994; 94: 2009-2019. [CrossRef]

26. Bomzon A. Bile acids, oxidative stress and renal function in biliary obstruction Semin Nephro 1997; 17: 549-562.

27. Kucuk C, Sozuer E, Ikizceli I, Avsarogullari L, Keceli M, Akgun H, et al. Role of oxygen free radical scavengers in acute renal failure complicating obstructive jaundice. Eur Surg Res 2003; 35: 143-147.[CrossRef] 